\title{
Management of renin-angiotensin-aldosterone inhibitors and other antihypertensives and their clinical effects on pre-anesthesia blood pressure
}

Received May 22, 2021

Revised October 11, 2021

Accepted October 23, 2021

\section{Corresponding author}

Eda Balcı, M.D.

Department of Anesthesiology, Ankara

City Hospital, Health Sciences

University, Universiteler District,

Bilkent Street No:1, Ankara 06800,

Turkey

Tel: 90-5336297760

Fax: 90-3125526000

E-mail: edaaksoy84@gmail.com

\author{
Eda Balcı' , Zeliha Aslı Demir', and Melike Bahçecitapar²
}

${ }^{1}$ Department of Anesthesiology, Ankara City Hospital, Health Sciences University, ${ }^{2}$ Department of Statistics, Hacettepe University, Ankara, Turkey
Background: Blood pressure fluctuations appear more significant in patients with poorly controlled hypertension and are known to be associated with adverse perioperative morbidity. In the present study, we aimed to determine the effects of antihypertensive drug treatment strategies on preanesthetic operating room blood pressure measurements.

Methods: A total of 717 patients participated in our study; 383 patients who were normotensive based on baseline measurements and not under antihypertensive therapy were excluded from the analysis. The remaining 334 patients were divided into six groups according to the antihypertensive drug treatment. These six groups were examined in terms of preoperative baseline and pre-anesthesia blood pressure measurements.

Results: As a result of the study, it was observed that $24 \%$ of patients had high blood pressure precluding surgery, and patients using renin-angiotensin-aldosterone system inhibitors (RAASI) had higher pre-anesthesia systolic blood pressure than patients using other antihypertensive drugs. Patients who received beta-blockers were also observed to have the lowest pre-anesthesia systolic blood pressure, diastolic blood pressure, and mean blood pressure, compared to others.

Conclusions: Recently, whether RAASI should be continued preoperatively remains controversial. Our study shows that RAASI cannot provide optimal pre-anesthesia blood pressure and lead to an increase in the number of postponed surgeries, probably due to withdrawal of medication before the operation. Therefore, the preoperative discontinuation of RAASI should be reevaluated in future studies.

Keywords: Anti-Hypertensive agents; Blood pressure; Pre-operative hypertension; Pre-anesthesia hypertension.

\section{INTRODUCTION}

Hypertension is a global public health problem and a preventable cause of mortality and morbidity. It has an estimated prevalence of $30 \%$ [1]. In untreated patients, hypertension is known to increase the risk of cardiovascular and cerebrovascular events, bleeding, kidney injury, and mortality $[2,3]$.
In addition, poorly controlled blood pressure leads to cancelation or postponement of surgery [3]. Table 1 presents the classification of hypertension, as recommended by the 2018 European Society of Cardiology (ESC) and European Society of Hypertension (ESH) guidelines for the management of arterial hypertension (Table 1) [4]. It is generally accepted that patients with grade 1 hypertension have little or no in-

This is an Open Access article distributed under the terms of the Creative Commons Attribution Non-Commercial License (http://creativecommons.org/licenses/by-nc/4.0) which permits unrestricted non-commercial use, distribution, and reproduction in any medium, provided the original work is properly cited.

Copyright (C) the Korean Society of Anesthesiologists, 2022 
Table 1. Classification of Blood Pressure and Definitions of Hypertension Grade, 2018 ESC/ESH Guidelines for the Management of Arterial Hypertension

\begin{tabular}{ll}
\hline \multicolumn{1}{c}{ Blood pressure classification } & $\begin{array}{c}\text { Systolic and diastolic pressure } \\
(\mathrm{mmHg})\end{array}$ \\
\hline Definition of hypertension & $>140 / 90$ \\
Grading of normal pressure & Optimal $<120 / 80$ \\
& Normal $120-129 / 80-84$ \\
& High normal 130-139/85-89 \\
Grading of hypertension & Grade 1 140-159/90-99 \\
& Grade 2 160-179/100-109 \\
& Grade 3 $\geq 180 / 110$ \\
\hline
\end{tabular}

ESC/ESH: European Society of Cardiology and the European Society of Hypertension.

creased risk of perioperative cardiac morbidity, and anesthesia can be performed as planned, whereas patients with grade 3 hypertension have an increased risk of severe end-organ damage and cardiac morbidity [5]. In this context, the $2018 \mathrm{ESC} / \mathrm{ESH}$ guidelines for the management of arterial hypertension and the 2017 American College of Cardiology (ACC) and American Heart Association (AHA) guidelines for the prevention, detection, evaluation, and management of high blood pressure in adults suggest that in those with systolic blood pressure (SBP) $\geq 180 \mathrm{mmHg}$ and/or diastolic blood pressure (DBP) $\geq 110 \mathrm{mmHg}$, deferring the intervention until blood pressure is reduced or controlled is advisable, except for emergencies $[4,6]$.

In patients receiving antihypertensive therapy, an important issue in the perioperative period is to avoid large blood pressure fluctuations. Fluctuations appear more significant in patients with poorly controlled hypertension and are usually accompanied by a significant increase during anesthesia induction followed by a serious decrease [7]. Intraoperative blood pressure instability is known to be associated with adverse perioperative morbidity, the most important of which are major adverse cardiac events and acute kidney injury $[1,2]$.

Antihypertensive treatment strategies have not been proven to be superior to each other in patients undergoing non-cardiac surgery; therefore, general antihypertensive treatment algorithms are applied in the perioperative period $[8,9]$. Accordingly, tight control of blood pressure in the perioperative period is more important than the type of drug therapy used. Nonetheless, renin-angiotensin-aldosterone system inhibitors (RAASIs) and beta-blockers (BBs) have been somewhat unusual in this regard, and they have caused great controversy over whether they should be continued or discontinued preoperatively. More recently, the continuation of BBs has been recommended for chronic usage [4]. Abrupt cessation of BBs may lead to withdrawal syndrome, sympathetic overactivity, and acute hypertension [10]. In recent days, it remains controversial whether RAASIs should be continued preoperatively. Discontinuation of RAASIs is claimed to reduce the risk of intraoperative hypotension and vasoplegia $[11,12]$ and is associated with a significant reduction in cardiovascular events and mortality 30 days after the intervention [13].

In the present observational study, we aimed to determine the effect of antihypertensive drug treatment strategies on pre-anesthesia operating room blood pressure and to investigate the effects of the adjustments made in patients using RAASI on pre-anesthesia blood pressure.

\section{MATERIALS AND METHODS}

A total of 717 adult patients were included in this prospective, cross-sectional, observational study in a tertiary hospital in Ankara, Turkey. We collected data on patients' demographic features during the preanesthetic examination, including past diagnosis and treatment of hypertension, comorbidities, and chronic medications. During the preoperative preparation, which is usually performed 2 weeks to 1 month before surgery at the hospital's outpatient clinics; SBP, DBP, and heart rate (HR) were taken as basal measurements. Blood pressure was measured using automatic blood pressure measurement machines (GE Healthcare B40 Patient Monitors, GE Healthcare, UK), from the upper arm, by cuffs according to body characteristics, after resting for 15 min. The patients were under routine antihypertensive therapy. In the operating room, pre-anesthesia measurements were taken before anesthesia induction (GE Healthcare B650 Carescape Monitors, GE Healthcare). Patients with non-hypertensive basal measurements without antihypertensive therapy were evaluated in our previous study [14]. Patients with $\mathrm{SBP} \geq 140$ and/or DBP $\geq 90 \mathrm{mmHg}$ at basal measurements and/or patients receiving antihypertensive therapy were included in the study. These patients were divided into six groups according to antihypertensive drug treatments: group none, group RAAS inhibitors (RAASI), group beta blockers (BB), group calcium channel blockers (CCB), group diuretics (D), and group combined (Co) (Fig. 1). Patients without antihypertensive therapy, although basal measurements were SBP $\geq 140 \mathrm{mmHg}$ and/or DBP $\geq 90 \mathrm{mmHg}$, were referred to as group none. Each measurement consisted of three separate measurements taken over a 15-min pe- 


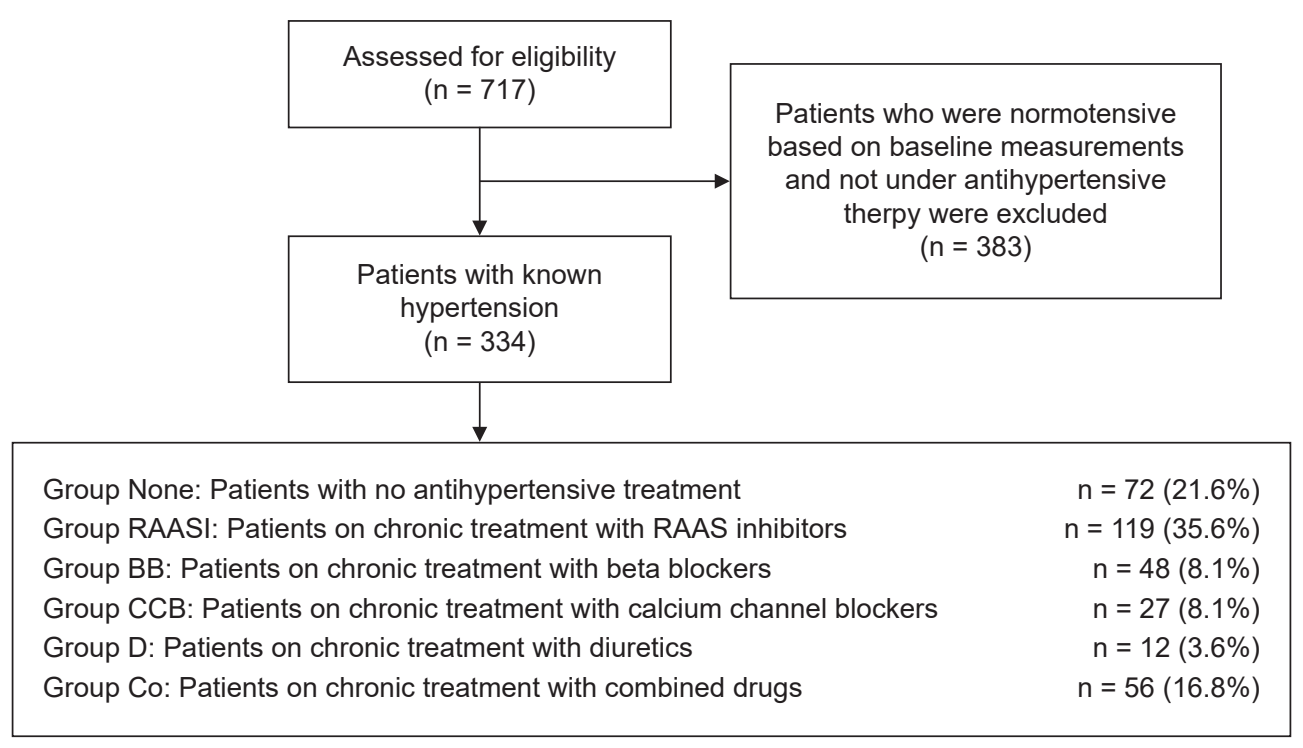

Fig. 1. Flow diagram. RAASI: renin-angiotensin-aldosterone system inhibitors, BB: beta blockers, CCB: calcium channel blockers, D: diuretics, Co: combined.

riod with 5-min intervals, after which the highest values were recorded. Blood pressure measurements were measured using automatic blood pressure measurement machines from the upper arm, by cuffs according to body characteristics. Patients were not premedicated with an anxiolytic or analgesic agent. After the measurements, the operation was started with the appropriate anesthetic method for the patient. Intraoperative and postoperative data were not included in this study, and blood pressure data obtained from the basal and operating room measurements were analyzed. Elective surgeries were postponed in patients with pre-anesthesia SBP $\geq 180$ and/or DBP $\geq 110 \mathrm{mmHg}$, as recommended by the latest guidelines $[4,6]$.

Patients undergoing emergency surgery and patients under the age of 18, patients whose basal measurements were normotensive while not under antihypertensive therapy, and patients who received antihypertensive therapy but did not comply with the treatment protocol, and whose treatment protocol was changed after the basal measurements were excluded from the study. As required by the routine practice of our clinic, patients took non-RAASI antihypertensive drugs until the morning of the operation, and patients using RAASI discontinued using RAASI $10-12 \mathrm{~h}$ before the operation.

This study complied with the Declaration of Helsinki, and ethical approval was granted by the local institutional ethical board (no. 13226/19.12.2017). Informed consent was obtained from all patients.

\section{Statistical methods}

Statistical analyses were performed using IBM SPSS Statistics for Windows, version 22.0 (IBM Co., NY, USA). In order to describe the basic features of patients, mean, standard deviation (SD), minimum and maximum values for normally distributed continuous variables, median, 1st quartile (1Q), and 3rd quartiles (3Q) for non-normally distributed continuous variables; the number of patients and their proportions for categorical variables were calculated as descriptive statistics. The Shapiro-Wilk test or the KolmogorovSmirnov test was used to investigate whether data were normally distributed. Comparisons among groups were performed using one-way analysis of variance (ANOVA) or Kruskal-Wallis test. The Games-Howell or least significant difference post hoc test was used for pairwise comparisons of groups, when the assumption of homogeneity of variance was violated or not for one-way ANOVA. Significance was set at $\mathrm{P}<0.05$, using two-sided comparisons.

\section{RESULTS}

A total of 717 adult non-cardiac elective surgery patients participated in this cross-sectional study. Among them, 383 patients who were normotensive based on baseline measurements (SBP $\leq 140$ and/or DBP $\leq 90 \mathrm{mmHg}$ ) and not under any antihypertensive therapy were excluded from the analysis. The remaining 334 patients were divided into six groups ac- 
cording to the antihypertensive drug treatment (Fig. 1). Table 2 presents the demographic data of the entire study population (Table 2). When the whole study population was evaluated in general, pre-anesthetic blood pressure measurements were SBP $163.58 \pm 24.43 \mathrm{mmHg}$, DBP $88.10 \pm 12.41 \mathrm{mmHg}$, and mean blood pressure (MBP) $113.25 \pm 14.63 \mathrm{mmHg}$.

Pre-anesthesia SBP, DBP, MBP, and HR measurements were significantly higher than preoperative measurements in all groups $(\mathrm{P}<0.001)$; however, DBP was not significantly different in group D (Table 3 ). There was a significant difference in preoperative SBP, DBP, MBP, and HR measurements between the groups $(\mathrm{P}<0.001, \mathrm{P}<0.001, \mathrm{P}=0.001$, and $\mathrm{P}$ $=0.032$, respectively). In group none, the preoperative measurements of SBP and DBP were significantly higher than those in the RAASI, BB, CCB, and Co groups, and the preoperative measurements of $\mathrm{MBP}$ were significantly higher than all other groups.

There was a significant difference in terms of pre-anesthesia SBP, DBP, MBP, and HR measurements between the groups ( $\mathrm{P}=0.046,0.006,0.004$, and 0.023 , respectively). In group none and group RAASI, pre-anesthesia measurements of SBP, DBP, and MBP were significantly higher than those in group $\mathrm{BB}(\mathrm{P}=0.006,0.004$, and 0.023 , respectively). Group BB had the lowest pre-anesthesia SBP, DBP, and MBP.

Table 3 also presents the pre-anesthesia blood pressure measurements in terms of the ESC/ESH 2018 classification in all groups (Table 3). A statistically significant difference was found between the groups when pre-anesthesia measurements were classified $\left(\chi^{2}=26.72, \mathrm{P}=0.031\right)$. For the majority of patients in the RAASI group (31.9\%), the pre-anesthesia blood pressure measurements were grade 3 . From another point of view, the majority of the 80 patients (47.5\%) with pre-anesthesia measurement grade 3 belong to group RAASI. Operations were deferred in patients with grade 3 pre-anesthesia blood pressure.

\section{DISCUSSION}

Hypertension can cause perioperative hemodynamic changes, which may be associated with perioperative morbidity and mortality [1]. As the number of patients undergoing surgery increases, management of perioperative hypertension has become a leading topic in clinical practice. We evaluated the effects of antihypertensive drugs on pre-anesthesia induction blood pressure measurements. As a general result of the study, it was observed that pre-anesthesia blood pressures of the patients were not at normotensive levels, and patients using RAASI had higher pre-anesthesia SBP and MBP than patients using other antihypertensive drugs. Patients with BB were also observed to have the lowest pre-anesthesia SBP, DBP, and MBP values. Antihypertensive drugs were chosen according to the patients' comorbidities. However, it also differs between guidelines. In this study, we evaluated antihypertensive drug therapies that were previously managed by cardiologists. Thirty-five percent of our study participants used angiotensin-converting enzyme inhibitors (ACEi) or angiotensin receptor blockers (ARBs) as monotherapy, while $16.8 \%$ of participants used combined drugs.

Table 2. Demographical Data of Groups

\begin{tabular}{|c|c|c|c|c|c|c|}
\hline Variable & $\begin{array}{l}\text { Group None } \\
(\mathrm{n}=72)\end{array}$ & $\begin{array}{c}\text { Group RAASI } \\
(\mathrm{n}=119)\end{array}$ & $\begin{array}{c}\text { Group BB } \\
(\mathrm{n}=48)\end{array}$ & $\begin{array}{l}\text { Group CCB } \\
(\mathrm{n}=27)\end{array}$ & $\begin{array}{l}\text { Group D } \\
(\mathrm{n}=12)\end{array}$ & $\begin{array}{l}\text { Group Co } \\
(n=56)\end{array}$ \\
\hline Male sex & $48(66.7)$ & $78(65.5)$ & $38(79.2)$ & $15(55.6)$ & $12(100)$ & $41(73.2)$ \\
\hline Age (yr) & $\begin{array}{c}57.33 \pm 13.34 \\
(21-93)\end{array}$ & $\begin{array}{c}64.77 \pm 9.88 \\
(37-92)\end{array}$ & $\begin{array}{l}61.81 \pm 9.76 \\
(45-84)\end{array}$ & $\begin{array}{c}60.85 \pm 15.45 \\
(33-85)\end{array}$ & $\begin{array}{c}66.00 \pm 5.34 \\
(53-72)\end{array}$ & $\begin{array}{l}67.11 \pm 10.03 \\
(40-87)\end{array}$ \\
\hline Body mass index $\left(\mathrm{kg} / \mathrm{m}^{2}\right)$ & $\begin{array}{l}0.28 \pm 0.06 \\
(0.16-0.57)\end{array}$ & $\begin{array}{l}0.29 \pm 0.05 \\
(0.18-0.49)\end{array}$ & $\begin{array}{l}0.27 \pm 0.04 \\
(0.15-0.37)\end{array}$ & $\begin{array}{l}0.27 \pm 0.04 \\
(0.21-0.36)\end{array}$ & $\begin{array}{l}0.31 \pm 0.05 \\
(0.24-0.40)\end{array}$ & $\begin{array}{l}0.28 \pm 0.04 \\
(0.20-0.37)\end{array}$ \\
\hline \multicolumn{7}{|l|}{ Comorbidities } \\
\hline Diabetes mellitus & $7(9.7)$ & $32(26.9)$ & $13(27.1)$ & $7(25.9)$ & $5(41.7)$ & $19(33.9)$ \\
\hline Coronary artery disease & $1(1.4)$ & $23(19.3)$ & $26(54.2)$ & $6(22.2)$ & $4(33.3)$ & $31(55.4)$ \\
\hline Cerebrovascular disease & - & $4(3.4)$ & $1(2.1)$ & $1(3.7)$ & $1(8.3)$ & $1(1.8)$ \\
\hline $\begin{array}{l}\text { Chronic obstructive } \\
\text { pulmonary disease }\end{array}$ & $8(11.1)$ & $14(11.8)$ & $5(10.4)$ & $2(7.4)$ & $4(33.3)$ & $5(8.9)$ \\
\hline Arrhythmia & $1(1.4)$ & $3(2.5)$ & - & $2(7.4)$ & - & $4(7.1)$ \\
\hline Hyperlipidemia & - & $2(1.7)$ & $7(14.6)$ & $2(7.4)$ & $1(8.3)$ & $6(10.7)$ \\
\hline Thyroid disease & $8(11.1)$ & $2(1.7)$ & $3(6.3)$ & $2(7.4)$ & $1(8.3)$ & $3(5.4)$ \\
\hline Renal disease & - & $2(1.7)$ & - & - & - & $5(8.9)$ \\
\hline
\end{tabular}

Values are presented as number (\%) or mean \pm SD (min-max). RAASI: renin-angiotensin-aldosterone system inhibitors, BB: beta blockers, CCB: calcium channel blockers, D: diuretics, Co: combined antihypertensives, -: not available. 
Table 3. Measurement Characteristics for Each Group

\begin{tabular}{|c|c|c|c|c|c|c|c|c|}
\hline Variable & $\begin{array}{l}\text { Group None } \\
\quad(n=72)\end{array}$ & $\begin{array}{l}\text { Group RAASI } \\
(\mathrm{n}=119)\end{array}$ & $\begin{array}{l}\text { Group BB } \\
(n=48)\end{array}$ & $\begin{array}{l}\text { Group CCB } \\
(\mathrm{n}=27)\end{array}$ & $\begin{array}{l}\text { Group D } \\
(n=12)\end{array}$ & $\begin{array}{l}\text { Group Co } \\
(n=56)\end{array}$ & $\begin{array}{c}\text { Total } \\
(\mathrm{n}=334)\end{array}$ & $P$ value \\
\hline \multicolumn{9}{|c|}{ Preoperative measurement } \\
\hline Normal/high normal & $1(1.4)$ & $66(55.5)$ & $30(62.5)$ & $16(59.3)$ & $4(33.3)$ & $34(60.7)$ & $151(45.2)$ & \\
\hline Grade I & $48(66.7)$ & $36(30.3)$ & $9(18.8)$ & $7(25.9)$ & $4(33.3)$ & $13(23.2)$ & $117(35.0)$ & \\
\hline Grade II & $23(31.9)$ & $15(12.6)$ & $8(16.7)$ & $2(7.4)$ & $2(16.7)$ & $9(16.1)$ & $59(17.7)$ & \\
\hline Grade III & - & $2(1.7)$ & $1(2.1)$ & $2(7.4)$ & $2(16.7)$ & - & $7(2.1)$ & \\
\hline $\begin{array}{l}\text { Systolic blood pressure } \\
(\mathrm{mmHg})\end{array}$ & $150(144,160)$ & $135(120,147)$ & $132(119,147)$ & $130(125,145)$ & $147(123,165)$ & $130(120,144)$ & $140(124,150)$ & $<0.001 *$ \\
\hline $\begin{array}{l}\text { Diastolic blood } \\
\text { pressure (mmHg) }\end{array}$ & $87(80,95)$ & $80(70,85)$ & $78(70,85)$ & $80(70,82)$ & $85(75,89)$ & $80(70,85)$ & $80(70,88)$ & $<0.001 *$ \\
\hline $\begin{array}{l}\text { Mean blood pressure } \\
(\mathrm{mmHg})\end{array}$ & $107(102,113)$ & $98(87,105)$ & $96(87,107)$ & $97(90,104)$ & $105(96,113)$ & $97(90,105)$ & $100(91,107)$ & $<0.001^{\dagger}$ \\
\hline Heart rate (beats/min) & $\begin{array}{l}80 \pm 13 \\
(56-115)\end{array}$ & $\begin{array}{l}75 \pm 12 \\
(50-108)\end{array}$ & $\begin{array}{l}73 \pm 13 \\
(50-120)\end{array}$ & $\begin{array}{l}77 \pm 11 \\
(60-99)\end{array}$ & $\begin{array}{c}76 \pm 9 \\
(60-89)\end{array}$ & $\begin{array}{l}74 \pm 12 \\
(50-110)\end{array}$ & $\begin{array}{c}76 \pm 12 \\
(50-120)\end{array}$ & \\
\hline \multicolumn{9}{|c|}{ Pre-anesthesia measurement } \\
\hline Normal/high normal & $3(4.2)$ & $15(12.6)$ & $14(29.2)$ & $4(14.8)$ & $1(8.3)$ & $7(12.5)$ & $44(13.2)$ & \\
\hline Grade I & $26(36.1)$ & $30(25.2)$ & $16(33.3)$ & $7(25.9)$ & $5(41.7)$ & $18(32.1)$ & $102(30.5)$ & \\
\hline Grade II & $27(37.5)$ & $36(30.3)$ & $12(25.0)$ & $12(44.4)$ & $4(33.3)$ & $17(30.4)$ & $108(32.3)$ & \\
\hline Grade III & $16(22.2)$ & $38(31.9)$ & $6(12.5)$ & $4(14.8)$ & $2(16.7)$ & $14(25.0)$ & $80(24.0)$ & \\
\hline $\begin{array}{l}\text { Systolic blood pressure } \\
(\mathrm{mmHg})\end{array}$ & $\begin{array}{l}165 \pm 22 \\
(120-257)\end{array}$ & $\begin{array}{c}167 \pm 24 \\
(110-232)\end{array}$ & $\begin{array}{l}153 \pm 25 \\
(111-237)\end{array}$ & $\begin{array}{l}161 \pm 20 \\
(118-212)\end{array}$ & $\begin{array}{l}166 \pm 22 \\
(138-215)\end{array}$ & $\begin{array}{l}161 \pm 25 \\
(108-228)\end{array}$ & $\begin{array}{l}163 \pm 24 \\
(110-257)\end{array}$ & $0.046^{\ddagger}$ \\
\hline $\begin{array}{l}\text { Diastolic blood } \\
\text { pressure (mmHg) }\end{array}$ & $\begin{array}{l}91 \pm 11 \\
(68-123)\end{array}$ & $\begin{array}{l}88 \pm 12 \\
(60-130)\end{array}$ & $\begin{array}{l}82 \pm 11 \\
(60-118)\end{array}$ & $\begin{array}{l}88 \pm 9 \\
(71-105)\end{array}$ & $\begin{array}{l}90 \pm 15 \\
(72-127)\end{array}$ & $\begin{array}{l}87 \pm 13 \\
(59-146)\end{array}$ & $\begin{array}{l}88 \pm 12 \\
(59-146)\end{array}$ & $0.006^{\ddagger}$ \\
\hline $\begin{array}{l}\text { Mean blood pressure } \\
(\mathrm{mmHg})\end{array}$ & $115(107,125)$ & $113(103,126)$ & $103(97,113)$ & $113(105,121)$ & $111(104,119)$ & $111(103,120)$ & $112(103,120)$ & $0.004^{\S}$ \\
\hline Heart rate (beats/min) & $86(75,98)$ & $80(68,90)$ & $78(70,85)$ & $82(72,90)$ & $82(68,100)$ & $80(67,88)$ & $80(70,90)$ & \\
\hline
\end{tabular}

Values are presented as number (\%), median (1Q, 3Q), or mean \pm SD (min-max). RAASI: renin-angiotensin-aldosterone system inhibitors, BB: beta blockers, CCB: calcium channel blockers, D: diuretics, Co: combined anti-hypertensives, SBP: systolic blood pressure, DBP: diastolic blood pressure, MBP: mean blood pressure. *A statistically significant difference was found between the six groups in terms of preoperative SBP and DBP. Groups that are different from each other; group none-RAASI; group none-BB; group none-CCB; group noneCo. ${ }^{\dagger} \mathrm{A}$ statistically significant difference was found between the six groups in terms of preoperative MBP. Groups that are different from each other; group none-RAASI; group none-BB; group none-CCB; group none-D; group none-Co; group RAASI-BB; group RAASI-CCB; group RAASI-D; group RAASI-Co. ${ }^{\ddagger} A$ statistically significant difference was found between the six groups in terms of pre-anesthesia SBP and DBP. Groups that are different from each other; group none-BB; group RAASI-BB. ${ }^{\S} \mathrm{A}$ statistically significant difference was found between the six groups in terms of pre-anesthesia MBP. Groups that are different from each other; group none-BB; group RAASI-CCB.

RAASIs are commonly used to treat hypertension. They act by inhibiting the renin-angiotensin-aldosterone system and include ACEi, ARBs, and direct renin inhibitors. ACEi is recommended as a first- or second-line therapy for the treatment of hypertension $[4,6]$. They are particularly important in blood pressure regulation in diabetic patients, as they prevent the development of diabetic nephropathy and are cardioprotective in patients recovering from myocardial infarction [15]. However, whether RAASI should be continued preoperatively remains controversial. Some studies suggest that RAASI may cause relative hypovolemia, which may predispose intraoperative hypotension $[16,17]$ and worsen mortality $[18,19]$, although others did not observe an association between the use of ACEi and intraoperative hypotension, complications, or increased 30-day mortality [15,17]. A re- view of Rosenman et al. [20] revealed that patients who received the immediate preoperative ACEi or ARB may be at increased risk for the development of perioperative hypotension; however, it is also claimed that there is inadequate evidence to determine whether hypotension leads to patient-important adverse outcomes. The 2018 ESC/ESH guidelines for the management of arterial hypertension suggest that "transient preoperative discontinuation of RAASi should be considered in patients with hypertension undergoing noncardiac surgery" as class IIa recommendation [4], and the 2017 ACC/AHA guideline for the prevention, detection, evaluation, and management of high blood pressure in adults suggests that "in patients with hypertension undergoing major surgery, discontinuation of ACEi or ARBs perioperatively may be considered" as class IIb recommendation [6], 
while the 2014 ACC/AHA guideline on perioperative cardiovascular evaluation and management of patients undergoing non-cardiac surgery suggests that "continuation of RAASI is reasonable perioperatively" as class IIa recommendation [21]. The ESC/ESH recommendation is consistent with a large prospective cohort study which suggested that withholding RAASI before major non-cardiac surgery was associated with a lower risk of death and postoperative vascular events [16]. We discontinued the RAASIs preoperatively in the morning $12 \mathrm{~h}$ before the operation as a routine hospital protocol even though the guidelines do not suggest any discontinuation duration before surgery. Our study results showed significantly higher pre-anesthesia SBP and MBP values in patients who used RAASI chronically before surgery and discontinued preoperatively. In our study population, $47 \%$ of the 80 patients whose operation was delayed due to grade 3 pre-anesthesia blood pressure were patients who discontinued the RAASI regimen preoperatively. Although the operation was not postponed, the majority of patients with grade 2 pre-anesthesia blood pressure (30.3\%) discontinued the RAASI regimen preoperatively. From another point of view, the majority (31.9\%) of pre-anesthesia blood pressure measurements of patients who discontinued RAASI was grade 3 .

BBs inhibit catecholamines at $\mathrm{G}$ protein-coupled $\beta$-adrenoreceptors and reduce blood pressure. This $\beta-1$ receptor blockade in the heart causes a reduction in HR and myocardial contractility. Blockade of the juxtaglomerular apparatus causes a reduction in renin secretion and salt and water retention [22]. The discontinuation of BBs prior to an operation has been a long debate, but recently, it has been suggested as a class Ib recommendation by the 2014 ACC/AHA and the $2018 \mathrm{ESC} / \mathrm{ESH}$ guidelines that patients who are currently under chronic BB treatment should continue their medication preoperatively $[4,21]$. This recommendation is based on the results of several studies which suggest that abrupt discontinuation of BBs is associated with higher rates of mortality and cardiac complications [9,23]. Our study showed that patients who were under chronic treatment with BBs had the lowest pre-anesthesia SBP, DBP, and MBP values. Moreover, their pre-anesthesia blood pressure values were mostly grade 1 (33.3\%). These results show that chronic BB treatment provides optimal pre-anesthesia blood pressure values. BBs are not generally used as first-line agents unless the patient needs secondary prevention following myocardial infarction [22]. In this regard, these results are valuable because patients with coronary artery disease tend to be more vulnerable to intraoperative blood pressure fluc- tuations caused by pre-anesthesia hypertension.

Why is an optimal pre-anesthesia blood pressure important? Preoperative hypertension can cause perioperative hemodynamic changes associated with perioperative morbidity and mortality, such as intraoperative hypotension and tachycardia $[24,25]$. It has been claimed that hypertensive patients may have greater cardiovascular lability and exaggerated hemodynamic stress response, particularly at the induction of anesthesia, due to increased catecholamine levels and increased sensitivity of peripheral vessels to catecholamines [26]. These blood pressure fluctuations may cause perioperative myocardial ischemia [27] and renal and cognitive impairment [28]. As a limitation of the present study, we did not analyze any intra- or postoperative data.

The above-mentioned issues predispose clinicians to avoid anesthetizing patients who are hypertensive before the induction of anesthesia. It is recommended to cancel elective surgery if SBP is $180 \mathrm{mmHg}$ or higher, or if the DBP is $110 \mathrm{mmHg}$ or higher [2,4]. Anesthesiologists are responsible for referring patients with elevated blood pressure to appropriate treatment during preassessment. However, in some cases, patients may be out of order, and blood pressure which was controlled during preassessment may be unexpectedly elevated before anesthesia induction and put both the patient and the anesthetist in difficulty. Besides hemodynamic problems, this unexpected hypertension may lead to the postponement of surgery and an increase in labor costs and hospital expenses.

Frequently, antihypertensive drugs are administered in the morning to reduce daytime blood pressure surges. However, the confirmed 24-h blood pressure patterns show a morning surge, which is a complex neurohormonal phenomenon that is especially related to the activation of the sympathetic nervous system upon awakening [29]. In our study group, emotional stress against the operation may be an additional factor for morning surges. Recently, several studies had a special interest in this subject because morning hours have the highest rate of major cardiovascular events $[29,30]$.

Chronotherapy involves moving one or more antihypertensives from morning to nighttime dosing to prevent a morning surge in blood pressure. It is claimed that nighttime dosing promotes 24 -h blood pressure profiles and does not cause an additional risk; therefore, it is recommended in the general population [30]. In our opinion, to reduce the additional risk of surgery-related stress and blood pressure elevations, the morning doses may be moved to nighttime dos- 
es adequate time before the operation.

The limitations of the present study include the fact that we analyzed pre-anesthetic data only and did not collect intraoperative or postoperative data. In addition, there were relatively small-sized groups; however, we did not exclude them and presented all patients' data.

In conclusion, it was found that pre-anesthesia SBP and MBP were higher in patients using RAASI than in patients using other antihypertensive drugs, and the lowest pre-anesthesia SBP, DBP, and MBP values were found in patients using BB. RAASI discontinuation 10-12 h before the operation does not provide optimal pre-anesthesia blood pressure and may not be replaced by another medicine after its discontinuation before the operation leads to an elevation in blood pressure, that is, an increase in the number of postponed surgeries. In this context, we propose that another medicine should be given as replacement after cessation of RAASI, or the antihypertensives that patients used chronically may be administered as nighttime doses in accordance with the chronotherapy principle. This issue should be re-evaluated in future studies.

\section{FUNDING}

None.

\section{CONFLICTS OF INTEREST}

No potential conflict of interest relevant to this article was reported.

\section{DATA AVAILABILITY STATEMENT}

The datasets generated during and/or analyzed during the current study are available from the corresponding author on reasonable request.

\section{AUTHOR CONTRIBUTIONS}

Conceptualization: Eda Balcı, Zeliha Aslı Demir, Melike Bahçecitapar. Data curation: Eda Balcı, Zeliha Aslı Demir, Melike Bahçecitapar. Formal analysis: Zeliha Aslı Demir, Melike Bahçecitapar. Methodology: Eda Balcı, Zeliha Aslı Demir, Melike Bahçecitapar. Project administration: Eda Balcı. Visualization: Eda Balcı. Writing - original draft: Eda Balcı. Writing - review \& editing: Eda Balcı, Zeliha Aslı Demir, Melike Bahçecitapar. Supervision: Zeliha Aslı Demir.

\section{ORCID}

Eda Balc1, https://orcid.org/0000-0002-8113-4080

Zeliha Aslı Demir, https://orcid.org/0000-0003-3053-0443

Melike Bahçecitapar, https://orcid.org/0000-0002-5443-6278

\section{REFERENCES}

1. Crowther M, van der Spuy K, Roodt F, Nejthardt MB, Davids JG, Roos J, et al. The relationship between pre-operative hypertension and intra-operative haemodynamic changes known to be associated with postoperative morbidity. Anaesthesia 2018; 73: 812-8.

2. Aronow WS. Management of hypertension in patients undergoing surgery. Ann Transl Med 2017; 5: 227.

3. Wong D, Tsai PNW, Ip KY, Irwin MG. New antihypertensive medications and clinical implications. Best Pract Res Clin Anaesthesiol 2018; 32: 223-35.

4. Williams B, Mancia G, Spiering W, Agabiti Rosei E, Azizi M, Burnier M, et al. ESC Scientific Document Group. 2018 ESC/ ESH guidelines for the management of arterial hypertension. Eur Heart J 2018; 39: 3021-104.

5. Dix P, Howell S. Survey of cancellation rate of hypertensive patients undergoing anaesthesia and elective surgery. Br J Anaesth 2001; 86: 789-93.

6. Whelton PK, Carey RM, Aronow WS, Casey DE Jr, Collins KJ, Dennison Himmelfarb C, et al. 2017 ACC/AHA/AAPA/ABC/ ACPM/AGS/APhA/ASH/ASPC/NMA/PCNA guideline for the prevention, detection, evaluation, and management of high blood pressure in adults: a report of the American College of Cardiology/American Heart Association task force on clinical practice guidelines. Hypertension 2018; 71: e13-115.

7. Wolfsthal SD. Is blood pressure control necessary before surgery? Med Clin North Am 1993; 77: 349-63.

8. Bouri S, Shun-Shin MJ, Cole GD, Mayet J, Francis DP. Meta-analysis of secure randomised controlled trials of $\beta$-blockade to prevent perioperative death in non-cardiac surgery. Heart 2014; 100: 456-64.

9. Blessberger H, Kammler J, Domanovits H, Schlager O, Wildner B, Azar D, et al. Perioperative beta-blockers for preventing surgery-related mortality and morbidity. Cochrane Database Syst Rev 2018; 3: CD004476.

10. Karachalios GN, Charalabopoulos A, Papalimneou V, Kiortsis D, Dimicco P, Kostoula OK, et al. Withdrawal syndrome following cessation of antihypertensive drug therapy. Int J Clin Pract 2005; 59: 562-70.

11. Kristensen SD, Knuuti J, Saraste A, Anker S, Bøtker HE, Hert SD, 
et al. Authors/Task Force Members. 2014 ESC/ESA guidelines on non-cardiac surgery: cardiovascular assessment and management: the Joint Task Force on non-cardiac surgery: cardiovascular assessment and management of the European Society of Cardiology (ESC) and the European Society of Anaesthesiology (ESA). Eur Heart J 2014; 35: 2383-431.

12. Zou Z, Yuan HB, Yang B, Xu F, Chen XY, Liu GJ, et al. Perioperative angiotensin-converting enzyme inhibitors or angiotensin II type 1 receptor blockers for preventing mortality and morbidity in adults. Cochrane Database Syst Rev 2016; 2016: CD009210.

13. Ward AM, Takahashi O, Stevens R, Heneghan C. Home measurement of blood pressure and cardiovascular disease: systematic review and meta-analysis of prospective studies. J Hypertens 2012; 30: 449-56.

14. Balci E, Demir A, Bahcecitapar M, Karadeniz U. Diagnosed in operating room with hypertension: a widespread but unseen affliction. Blood Press Monit 2020; 25: 136-41.

15. Turan A, You J, Shiba A, Kurz A, Saager L, Sessler DI. Angiotensin converting enzyme inhibitors are not associated with respiratory complications or mortality after noncardiac surgery. Anesth Analg 2012; 114: 552-60.

16. Roshanov PS, Rochwerg B, Patel A, Salehian O, Duceppe E, Belley-Côté EP, et al. Withholding versus continuing angiotensin-converting enzyme inhibitors or angiotensin II receptor blockers before noncardiac surgery: an analysis of the vascular events in noncardiac surgery patients cohort evaluation prospective cohort. Anesthesiology 2017; 126: 16-27.

17. Kheterpal S, Khodaparast O, Shanks A, O’Reilly M, Tremper KK. Chronic angiotensin-converting enzyme inhibitor or angiotensin receptor blocker therapy combined with diuretic therapy is associated with increased episodes of hypotension in noncardiac surgery. J Cardiothorac Vasc Anesth 2008; 22: 180-6.

18. Miceli A, Capoun R, Fino C, Narayan P, Bryan AJ, Angelini GD, et al. Effects of angiotensin-converting enzyme inhibitor therapy on clinical outcome in patients undergoing coronary artery bypass grafting. J Am Coll Cardiol 2009; 54: 1778-84.

19. Railton CJ, Wolpin J, Lam-McCulloch J, Belo SE. Renin-angiotensin blockade is associated with increased mortality after vascular surgery. Can J Anaesth 2010; 57: 736-44.

20. Rosenman DJ, McDonald FS, Ebbert JO, Erwin PJ, LaBella M, Montori VM. Clinical consequences of withholding versus administering renin-angiotensin-aldosterone system antagonists in the preoperative period. J Hosp Med 2008; 3: 319-25.

21. Fleisher LA, Fleischmann KE, Auerbach AD, Barnason SA, Beckman JA, Bozkurt B, et al. 2014 ACC/AHA guideline on perioperative cardiovascular evaluation and management of patients undergoing noncardiac surgery: executive summary: a report of the American College of Cardiology/American Heart Association task force on practice guidelines. Circulation 2014; 130: 2215-45.

22. Howell SJ. Preoperative hypertension. Curr Anesthesiol Rep 2018; 8: 25-31.

23. Kwon S, Thompson R, Florence M, Maier R, McIntyre L, Rogers T, et al. Surgical Care and Outcomes Assessment Program (SCOAP) Collaborative. $\beta$-blocker continuation after noncardiac surgery: a report from the surgical care and outcomes assessment program. Arch Surg 2012; 147: 467-73.

24. Hartle A, McCormack T, Carlisle J, Anderson S, Pichel A, Beckett $\mathrm{N}$, et al. The measurement of adult blood pressure and management of hypertension before elective surgery: joint guidelines from the Association of Anaesthetists of Great Britain and Ireland and the British Hypertension Society. Anaesthesia 2016; 71: 326-37.

25. Charlson ME, MacKenzie CR, Gold JP, Ales KL, Topkins M, Shires GT. Preoperative characteristics predicting intraoperative hypotension and hypertension among hypertensives and diabetics undergoing noncardiac surgery. Ann Surg 1990; 212: 66-81.

26. Kihara S, Brimacombe J, Yaguchi Y, Watanabe S, Taguchi N, Komatsuzaki T. Hemodynamic responses among three tracheal intubation devices in normotensive and hypertensive patients. Anesth Analg 2003; 96: 890-5.

27. Venkatesan S, Myles PR, Manning HJ, Mozid AM, Andersson C, Jørgensen ME, et al. Cohort study of preoperative blood pressure and risk of 30-day mortality after elective non-cardiac surgery. Br J Anaesth 2017; 119: 65-77.

28. Vázquez-Narváez KG, Ulibarri-Vidales M. The patient with hypertension and new guidelines for therapy. Curr Opin Anaesthesiol 2019; 32: 421-6.

29. Bilo G, Grillo A, Guida V, Parati G. Morning blood pressure surge: pathophysiology, clinical relevance and therapeutic aspects. Integr Blood Press Control 2018; 11: 47-56.

30. Bowles NP, Thosar SS, Herzig MX, Shea SA. Chronotherapy for hypertension. Curr Hypertens Rep 2018; 20: 97. Erratum in: Curr Hypertens Rep 2018;21:1. 